\title{
EVALUATION OF BIOCHEMICAL AND QUALITY ATTRIBUTES TO MONITOR THE APPLICATION OF HEAT AND COLD TREATMENTS IN TOMATO FRUIT (LYCOPERSICON ESCULENTUM MILL.)
}

\author{
GUSTAVO POLENTA ${ }^{1,4}$, CLAUDIO BUDDE ${ }^{2}$, DHARINI SIVAKUMAR ${ }^{3}$, MARIANA NANNI $^{1}$ and \\ SILVINA GUIDI ${ }^{1}$ \\ ${ }^{1}$ Instituto de Tecnologia de Alimentos, Instituto Nacional de Tecnología Agropecuaria (INTA), Hurlingham, Buenos Aires, Argentina \\ 2Estación Agropecuaria San Pedro, Instituto Nacional de Tecnología Agropecuaria (INTA), San Pedro, Buenos Aires, Argentina \\ ${ }^{3}$ Postharvest Technology Group, Department of Crop Science, Tshwane University of Technology, Pretoria, South Africa
}

\author{
${ }^{4}$ Corresponding author. \\ TEL: 54-011-4621-0446/0457 Ext. 126; \\ FAX: 54-011-4621-2012; \\ EMAIL: polenta.gustavo@inta.gob.ar
}

Received for Publication December 16, 2013 Accepted for Publication January 2, 2015

$10.1111 /$ jfq. 12139

\begin{abstract}
The study was accomplished to optimize the application of stress treatment to prevent chilling injury $(\mathrm{CI})$ in tomatoes. Four treatments were evaluated: control, heat shock applied for 24 (HS24) and $48 \mathrm{~h}$ (HS48), and cold shock applied for $24 \mathrm{~h}$ (CS24). The fruits were stored at 2 and 14C, and evaluated immediately after treatment and after 21 and 28 days of storage. An additional evaluation after 7 days of exposure at 20C following storage withdrawal was included to induce ripening and exteriorize the development of CI symptoms. Different biochemical and quality attributes were evaluated (color, titratable acidity, firmness, ethylene, CI index and heat shock protein [HSP] accumulation). Heat treatments were successful in preventing the decay of fruits under CI-inducing conditions. The significantly better performance of HS48 in comparison to the other treatments gives evidence that the effectiveness relies on the adequate intensity of application; therefore, this intensity should be strictly controlled by a proper monitoring method. In this regard, small HSP accumulation was found suitable to reflect properly the physiological condition of fruits and therefore to potentially optimize and determine the adequate intensity of treatment application.
\end{abstract}

\section{PRACTICAL APPLICATIONS}

Stress treatments constitute a promising technological alternative to extend the shelf life of fruits and vegetables because of their capacity to prevent the development of chilling injury during the cold storage of sensitive species. The main advantages are the ease of use, considering that they can be applied in commercial chambers with minor changes, and the avoidance of chemicals. By assessing the effectiveness of treatments and the suitability of different biochemical and quality attributes as monitoring parameters to maximize the efficiency of application, it became apparent that the adequate intensity of application must be accurately established, since beyond a certain limit, the effect of the stress may induce irreversible alterations, provoking a permanent damage. The study provides evidence that small heat shock protein accumulation constitutes suitable monitoring parameters to objectively establish the optimal intensity, able to maintain the quality characteristics and extend the shell life of tomatoes during the cold storage. 


\section{INTRODUCTION}

The optimal temperature for the storage of tomatoes harvested at the usual commercial maturity (mature green) is known to be between 12.5 and 15C. Within this range, tomatoes can be maintained for approximately 14 days without reduction of sensory quality. Although a lower temperature could potentially extend the shelf life by delaying the ripening process, the storage below the lower limit can induce the development of a series of physiological disorders collectively known as chilling injury (CI).

Symptoms characteristic of CI in tomatoes include the development of depressions below the epidermal layer ("pitting"), the lack of superficial color uniformity, the increase in respiration rate and ethylene production, and a higher susceptibility to microbial attack (Paull 1990; Lurie and Klein 1991). The increased rate of decay has been directly related to the weakening of the epidermal layer, which predisposes to the infection by opportunistic microorganisms such as Alternaria spp., Stemphylium spp., Penicillium spp. and Aureobasidium spp. (Efiuvwevwere and Thorne 1988).

Among the alternatives proposed to prevent the development of CI, different studies have focused on the prestorage application of a thermal shock, which would be able to increase the tolerance of the produce to the low temperatures of storage (Lurie and Klein 1991; Lurie et al. 1993). The acquisition of this tolerance has been linked to the synthesis and persistence of a specific group of proteins referred to as heat shock proteins (HSPs) (Sabehat et al. 1996; Polenta et al. 2007). HSPs exert their protective role by participating in different biochemical processes such as the stabilization of proteins and membranes, and the refolding of proteins under stress conditions (Wang et al. 2004). This group of proteins has been proposed as biochemical markers to indicate the exposure of fruits and vegetables to a CI-inducing condition (Aghdam et al. 2013).

Similarly to the heat shock, the prestorage exposure of fruit to low temperatures (termed cold stress) can also potentially prevent the development of physiological disorders, since the biochemical response evoked by this condition, including the synthesis of HSP, is similar to that induced by a high temperature stress (Sung et al. 2003). The use of cold stress in postharvest technology offers some advantages, for instance, those related to packinghouse logistic. It has been reported that a low-temperature conditioning can have beneficial effect when applied prior to the disinfestation cold treatments required for the entry of fruits into many markets (Woolf et al. 2003).

Since the protective effect of stress treatments is usually verified for a narrow range of intensities, beyond which the effect can become deleterious (Polenta et al. 2007), it is necessary to count with reliable methods to determine the most adequate conditions to maximize the preservation of and avoid the alteration of fruit by the treatment itself.

In the present research, we conducted a comparative study between cold and heat stress treatments in tomatoes to better understand the physiological and biochemical bases of stress protection and to identify the most useful variables to monitor the application with the ultimate aim to improve and maximize the effectiveness of stress treatments.

\section{MATERIALS AND METHODS}

\section{Plant Material}

Tomatoes (Lycopersicon esculentum Mill. cv. Fortaleza) were used as experimental model. This is a commercial variety (Syngenta), which was chosen because of their suitable productive features such as high relation fruit/canopy, its ability to withstand low temperature, their excellent quality attributes such as color, firmness and size, and its resistance to different pests.

Uniform medium-sized mature, green tomatoes Grade 1 according to USDA (1976) were picked from a greenhouse, surface-sterilized for $3 \mathrm{~min}$ with a chlorine solution (150 ppm as $\mathrm{Cl}_{2}$ ), thoroughly rinsed with tap water for another $3 \mathrm{~min}$ and left to drain on filter paper.

\section{Stress Treatments}

Tomatoes were divided into four lots, each of them subjected to one of the following treatments:

(1) Untreated, used as a control $=\mathrm{C}$;

(2) 24-h heat treatment (incubation at 39C and 95\% relative humidity for $24 \mathrm{~h}$ ) = HS24;

(3) 48-h heat treatment (incubation at 39C and 95\% relative humidity for $48 \mathrm{~h}$ ) = HS48;

(4) 24-h cold treatment (incubation at $0 \mathrm{C}$ and $95 \%$ relative humidity for $24 \mathrm{~h}$ ) $=$ CS24.

The CI-inducing condition was established by a temperature considerably lower than the threshold for the damage (2C) and by storage times longer enough to induce the development of symptoms (21 and 28 days). Storage at $14 \mathrm{C}$ was included as the optimal storage temperature. Based on this information, the experimental design included four treatments (C, HS24, HS48 and CS24); two storage temperatures per treatment (2 and 14C); three sampling periods: immediately after treatment, and after 21 and 28 days of storage; two evaluation conditions for each sampling: immediately after cold withdrawal and after 7 days of exposure at $20 \mathrm{C}$ in a chamber to simulate commercial conditions and induce ripening of fruit. 


\section{Fruit Firmness Measurement}

Firmness was measured at the equatorial level on opposite sides of each individual fruit with a Shore A digitalized durometer (DUROFEL 10 licensee by CTIFL-France) and values were expressed by a scale range of 1-100, with higher values corresponding to firmer fruit.

\section{Titratable Acidity (TA)}

TA was determined in $10 \mathrm{~mL}$ of tomato juice $+100 \mathrm{~mL}$ of distilled water by titration with $0.1 \mathrm{M} \mathrm{NaOH}$ to $\mathrm{pH} 8.3$ and expressed as $\mathrm{g}$ malic acid/100 g tomato.

\section{Color Measurements}

Color measurements were performed with a Minolta Chroma Meter (CR 100 with 8-mm aperture) equipped with a data processor (DP-100, Minolta, Ramsey, NJ). The settings used were $L^{\star}, h^{\circ}$ and $C$, and the equipment was standardized with a Minolta standard white reflector plate. Three readings were performed in different areas of each individual fruit. Measurements were made at approximately $1 \mathrm{~cm}$ from the blossom scar. Maturity was evaluated by using the $h^{\circ}$ angle.

\section{Ethylene Production}

Ethylene production was analyzed with a Hewlett-Packard (Palo Alto, CA, USA) gas chromatograph (GC) on samples taken from the head space of sealed 1.5-L glass jars containing one fruit each for $1 \mathrm{~h} ; 3 \mathrm{~mL}$ of gas samples was withdrawn from the jars with a syringe through a rubber septum and injected into the GC. The equipment counted with an 80/100 mesh Porapak Q (Agilent, Santa Clara, CA, USA) column and a flame ionization detector. Oven temperature in the GC was $105 \mathrm{C}$, injector temperature was $100 \mathrm{C}$ and detector temperature was 250C. Nitrogen was used as carrier gas at a flow of $0.70 \mathrm{~mL} / \mathrm{s}$. Hydrogen at $0.55 \mathrm{~mL} / \mathrm{s}$ was burned in the presence of air at a flow of $6.67 \mathrm{~mL} / \mathrm{s}$. Ethylene concentration was expressed as $\mu \mathrm{L} / \mathrm{kg} / \mathrm{h}$.

\section{Cl Evaluation}

Since one of the main symptoms of CI in tomatoes is the increased rate of fungal infection, decay was evaluated visually as the presence of macroscopic fungal growth, and the corresponding percentage of diseased fruit was defined as the CI index (Efiuvwevwere and Thorne 1988; El Assi 2004).

\section{Protein Extraction}

Proteins were extracted from fruit pericarp following the method described by Hurkman and Tanaka (1986), and quantified by the Lowry method (Lowry et al. 1951).

\section{Sodium Dodecyl Sulfate-Polyacrylamide Gel Electrophoresis (SDS-PAGE)}

Electrophoresis was carried out according to the procedure of Laemmli (1970). Equal amount of proteins (18 $\mu \mathrm{g})$ were loaded onto each lane of a $12 \%$ polyacrylamide gel. The electrophoresis was run in a Mini Protean II Electrophoresis System (Bio-Rad, California, USA). Proteins were stained with a $0.1 \%(\mathrm{w} / \mathrm{v})$ Coomassie Brilliant Blue R-250 solution (Sigma, St. Louis, MO, USA).

\section{Immunoblots}

Separated polypeptides were transferred onto a nitrocelullose membrane by using a Mini Protean II Electrophoresis System (Bio-Rad). As the primary antibody, it was used as a commercial monoclonal antibody anti-HSP70 (clone BRM-22 Sigma (St. Louis, MO, USA), dilution 1:1500) or a polyclonal antiserum raised against a $21-\mathrm{kDa}$ HSP (HSP21) purified from tomato fruit (dilution 1:750). As the secondary antibody, it was used as either anti-mouse immunoglobulin $\mathrm{G}$ ( $\mathrm{IgG}$ ) for anti-HSP70 or anti-rabbit IgG for anti-HSP21, raised in goat and conjugated to alkaline phosphatase (Bio-Rad, dilution 1:1500). Membranes were revealed with nitroblue tetrazolium chloride and 5-bromo4-chloro-3-indolyil phosphate. Densitometric analysis was performed using the Quantity One software from Bio-Rad.

\section{Statistical Analysis}

A completely randomized design was used. Each evaluation condition involved four replications of four fruit each one. Significant differences were tested by analysis of variance (ANOVA) using the general linear model procedure of SAS software (SAS Institute, Cary, NC, USA). When significant main effects were observed, means separation was accomplished by the LSD (least significance difference) test.

In the case of ethylene, statistical tests were conducted on the transformed variables (logarithmic transformation), as previously reported in a study carried out by our group (Polenta et al. 2004). For a better visualization of the significance of the differences among treatment, LSD bar was included in Fig. 4.

\section{RESULTS AND DISCUSSION}

\section{Quality Parameters}

Fruit quality parameters were measured under three different conditions: immediately after treatment application, immediately after cold removal (after 21 and 28 days of storage) and after 7 days of exposure to room temperature following the cold removal ( 21 days +7 and 28 days +7 ). 
It is well known that symptoms of CI in tomatoes become apparent only after exposure of the chilled fruit to higher temperatures. This situation represents the main cause of postharvest losses in tomatoes, especially because of the development of symptoms such as uneven ripening or failure to ripen, and increased fungal infection (Efiuvwevwere and Thorne 1988). Therefore, the experiment included the evaluation of fruits withdrawn from cold and exposed at 20C for 7 days, which was called commercial condition. Although all attributes were evaluated under this condition, only the characteristics significantly affected by this situation are presented.

The use of stress treatments to prevent physiological disorders in fruits has been addressed in recent years in different investigations. While research has been mainly focused on heat treatments, there is a lack of comparative studies exploring, to a greater depth, the physiology and biochemical response of fruits subjected to different types of stresses. The present investigation was accomplished with the aim to gain a better comprehension on the basis of crossprotection, and to find the variables most suitable for monitoring the application and optimize performance of stress treatments.

Figure 1 shows that immediately after treatments, the heat exposure induced a higher softening rate compared with control fruit. After 28 days of storage, fruits treated for $24 \mathrm{~h}$ were less firm than control, regardless of the storage temperature, while no significant difference was found between control fruit and fruits submitted to HS48 and CS24.

Physiological variables are of paramount importance from the consumer point of view, although as shown in the present study, their potential for monitoring purposes is rather restricted. The effect of stress treatments on variables such as fruit firmness is highly dependent on the type of commodity. For instance, a delay in fruit softening has been reported in species such as apples (Lurie and Klein 1990), strawberries (Civello et al. 1997) and papaya (Paull and Chen 1990). On the contrary, tomatoes exposed to high temperatures and then incubated at 20C became significantly softer than fruits maintained during the entire period at 20C (Manzano-Mendez et al. 1984). In the present research, the rate of softening showed a positive correlation with the length of heat exposure for the high temperature treatments, although the cold treatment had no effect on this parameter. Therefore, it can be concluded that the physiological response associated with fruit firmness is not comparable for the different type of stresses, a fact that restricts its application for monitoring purposes.

The evaluation of TA showed a significant decrease in heated fruits, regardless of the storage temperatures (Fig. 2). In the case of fruits heated for $48 \mathrm{~h}$ (HS48), the decline was detected over the entire storage periods, while for HS24 treatment, only after 28 days of storage. After 28 days at 2C, there was a slight increased in TA level in fruits subjected to HS48 treatment.

TA is a variable associated with fruit taste that exhibited a positive correlation with treatment intensity, as shown in the present and previous investigations carried out by our group (Polenta et al. 2006). The reduction of this variable has been linked to the increased rate of respiration verified during the treatment, induced by high temperatures, which, in turn, accelerates the metabolism of organic acids (Lurie and Klein 1990). In the case of tomatoes, the main organic acid metabolized during heat treatments is malic acid (Polenta et al. 2006). During the storage period, different from what occurs during the treatment application, the respiration rate of heat-treated fruits can be was significantly

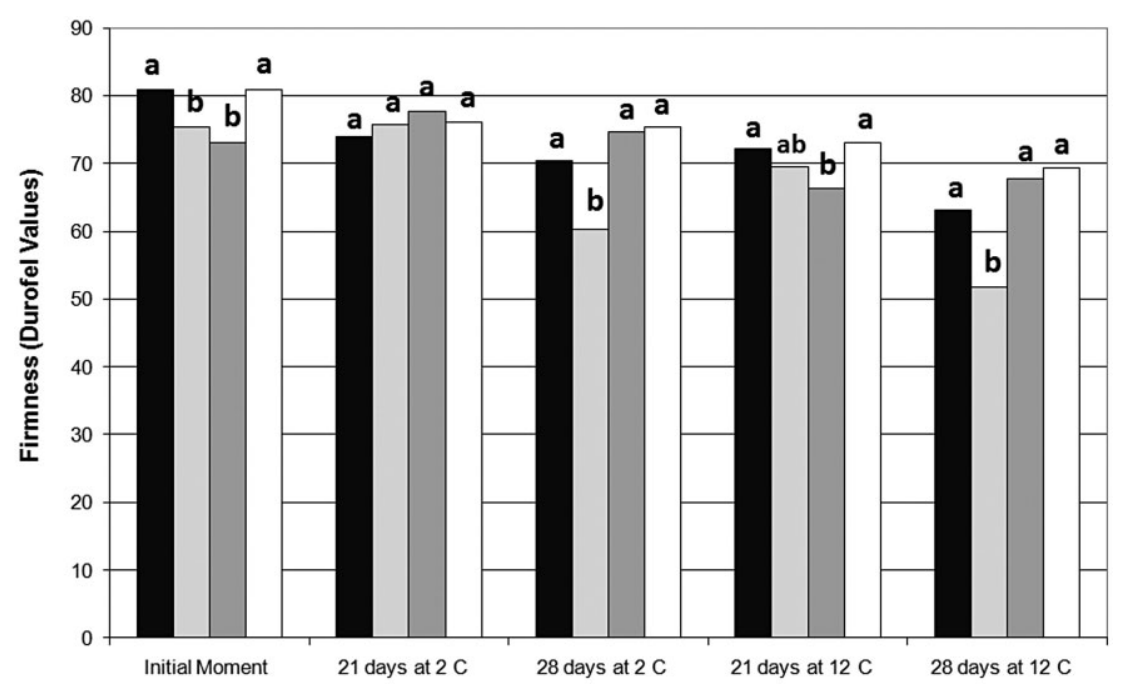

FIG. 1. DUROFEL VALUES OF TOMATOES UNTREATED (CONTROL), HEAT-TREATED FOR 24 HOURS (HS24), 48 HOURS (HS48), OR COLD-TREATED FOR 24 HOURS (CS24)

Fruit were analyzed after treatment application and at different sampling periods. Values with the same letter are not significantly different $(P<0.05)$. ( $\square)$ Control, ( $\square$ ) HS24, ( $\square)$ HS48, $(\square) \mathrm{CS} 24$ 
FIG. 2. TOTAL ACIDITY VALUES OF TOMATOES UNTREATED (CONTROL), HEATED FOR 24 HOURS (HS24), 48 HOURS (HS48), OR COOLED FOR 24 HOURS (CS24)

Fruit were analyzed after treatment application and at different sampling periods. Values with the same letter are not significantly different $(P<0.05)$. ( $\square)$ Control, $(\square) \mathrm{HS} 24$, $(\square) \mathrm{HS} 48$, $(\square) \mathrm{CS} 24$.

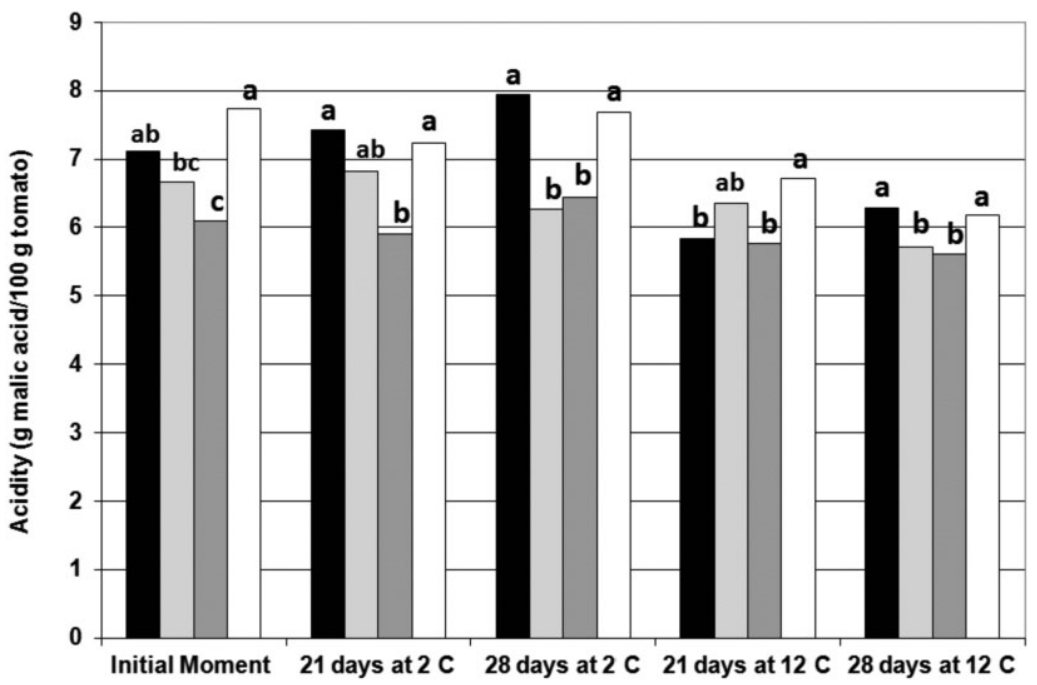

lower than that of untreated fruits (Fallik et al. 2000). This complex phenomenon could have been responsible for the slight increased evidenced in HS48 fruit during the storage at $2 \mathrm{C}$.

Similarly to the case of fruit firmness, cold treatment had no effect on this variable. Other variables associated with fruit taste such as total soluble solids are rather unaffected by heat treatments, as reported for apples (Lurie and Klein 1990) and tomatoes (McDonald et al. 1998).

Color (as evaluated by hue angles) was differently affected by HS48 and CS24 treatments. Immediately after treatment, hue angles were lower in HS48 than in control fruit, probably as a consequence of the accelerated ripening induced by the higher temperature. However, after 28 days of storage at 2C, the ripening was delayed in fruits submitted to this treatment. In the case of cold treatment, tomatoes showed a slower reddening rate during storage, a phenomenon detected at day 21 in fruits stored at $2 \mathrm{C}$, and at days 21 and 28 in fruits stored at $14 \mathrm{C}$ (Fig. 3A). Figure 3B shows hue angles in fruit exposed to commercial conditions. Immediately after treatment, heat-treated fruits had lower hue angles (redder color) than control and CS24 fruits. Similarly, when stored at 14C, HS24 and HS48 fruits showed a faster reddening rate than untreated fruit after 21 $(+7)$ days. Interestingly, quality parameters associated with appearance such as epidermal color were greatly affected by cold treatment, which was mostly evidenced when fruits were stored at $14 \mathrm{C}$.

Owing to the number and the complexity of the factors interacting with each other, which will eventually determine the visual appearance of the fruit, it is difficult to conduct a systematic analysis on the effect of stress treatments on color. This complexity determines that results related to this subject have been rather controversial among different investigations. For instance, color development was accelerated in apples and tomatoes heated for 4 days (Lurie and Klein 1990, 1991), but inhibited in tomatoes subjected to milder treatments (Sozzi et al. 1996). According to Paull and Chen (2000), the differential response among different studies is probably caused by variables not adequately controlled. The delay in reddening has been associated, in the case of tomatoes, with the inhibition of lycopene synthesis, a process particularly important when temperature rises above 32C (Dumas et al. 2002). On the contrary, the exposure of tomatoes to low temperatures can induce an erratic ripening behavior, with important differences with only a minor change in the storage temperature from 5 to $7 \mathrm{C}$ (Efiuvwevwere and Thorne 1988).

\section{Ethylene Production}

Figure 4 shows ethylene production in treated and control fruits. In the case of control fruit, the initial time $\left(t_{0}\right)$ was defined at the moment of harvest, while for the rest of the treatments (HS24, HS48 and CS24), $t_{0}$ was considered when fruit were removed from treatments. The results show that until day 4 , cold stress had little effect on ethylene production, with fruits subjected to CS24 showing an evolution similar to control. However, a plateau was apparently attained by control fruit at this time, while cold-treated fruits continued to increase until the end of the period of analysis.

Interestingly, heat treatments caused a notorious inhibition in ethylene synthesis, whose duration depended on the treatment intensity. In this regard, HS24 treatment caused a decline in ethylene synthesis, with only a residual production being detected after treatment removal $(t=0)$. When these fruits were placed at the temperature of evaluation 

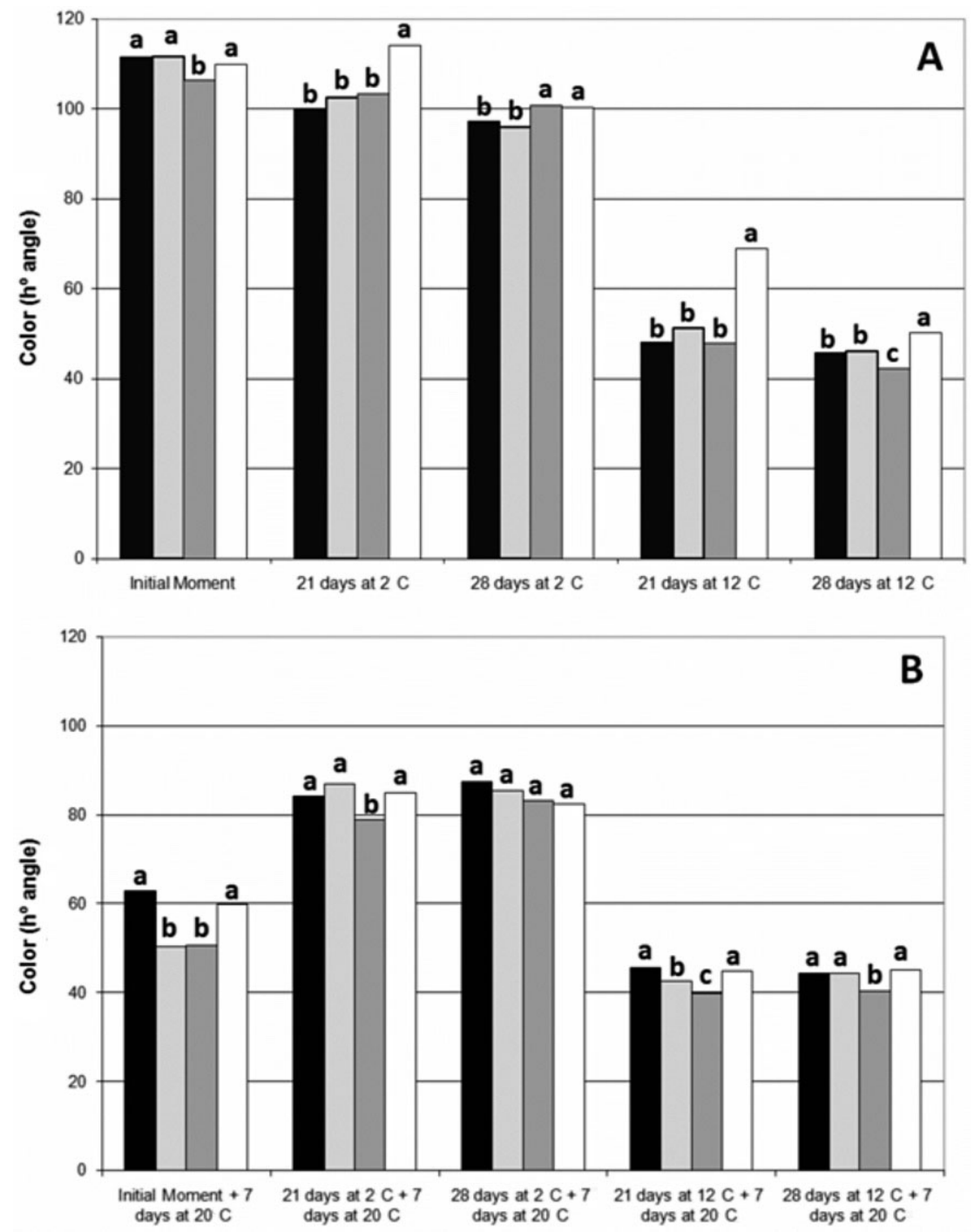

FIG. 3. HUE ANGLES OF TOMATOES UNTREATED (CONTROL), HEATED FOR 24 HOURS (HS24), 48 HOURS (HS48), OR COOLED FOR 24 HOURS (CS24)

Fruit were analyzed immediately after treatment application or storage (A), or after 7 days at $20 \mathrm{C}(\mathrm{B})$. Values with the same letter are not significantly different $(P<0.05)$. ( $\square)$ Control, ( $\square$ ) HS24, ( $\square$ ) HS48, ( $\square$ ) CS24.

(20C), ethylene level sharply rose to values similar to control within the first day, and even doubled control values by day 5 . Differently, ethylene production in fruits subjected to HS48 treatment was completely inhibited (with no detectable production at $t=0$ ), and this effect was only overcome after 2 days at 20C. After ethylene production was re-established, concentrations increased until reaching values similar to HS24 by day 5 .

Ethylene synthesis is significantly affected by temperature, a process that suggests its potential use as a monitoring variable. Although the qualitative aspect of the inhibition has been previously reported, the kinetic of this inhibition was not explored in depth. A previous research showed that the synthesis of this hormone was almost completely inhibited when tomatoes were held for 3 days at $38 \mathrm{C}$, although its synthesis was rapidly recovered when fruits were then transferred to 20C (Lurie et al. 1993).
The biochemical basis of this process has been linked to the last step of the pathway leading to ethylene synthesis (i.e., the conversion of ACC to ethylene), which is hindered when fruits are exposed to temperatures above $35 \mathrm{C}$ (Atta-Aly 1992). This inhibition would be due to the rapid loss of the enzyme ACC oxidase brings about by high temperatures, and whose full recovery may take as long as 3 days after heat removal. Since the first enzyme of the pathway (ACC synthase) is less sensitive to heat stress than ACC oxidase (Paull and Chen 2000), high levels of ACC are expected to accumulate during the exposure of fruits to temperatures between 35 and 45C. The high levels of ACC accumulated during the heat treatment, which are the substrate of ACC oxidase, are probably responsible for the sharp increase in ethylene production when normal temperatures are restored. This assumption is compatible with the finding of Lara et al. (2009), who reported that the 
FIG. 4. ETHYLENE PRODUCTION IN TOMATOES UNTREATED (CONTROL), HEATED FOR 24 HOURS (HS24), 48 HOURS (HS48) OR COOLED FOR 24 HOURS (CS24)

Fruit were analyzed after treatment and at different sampling periods. $(-\bullet)$ Control, $(-\triangle)$ HS24, (*×) HS48, (-๑) CS24.

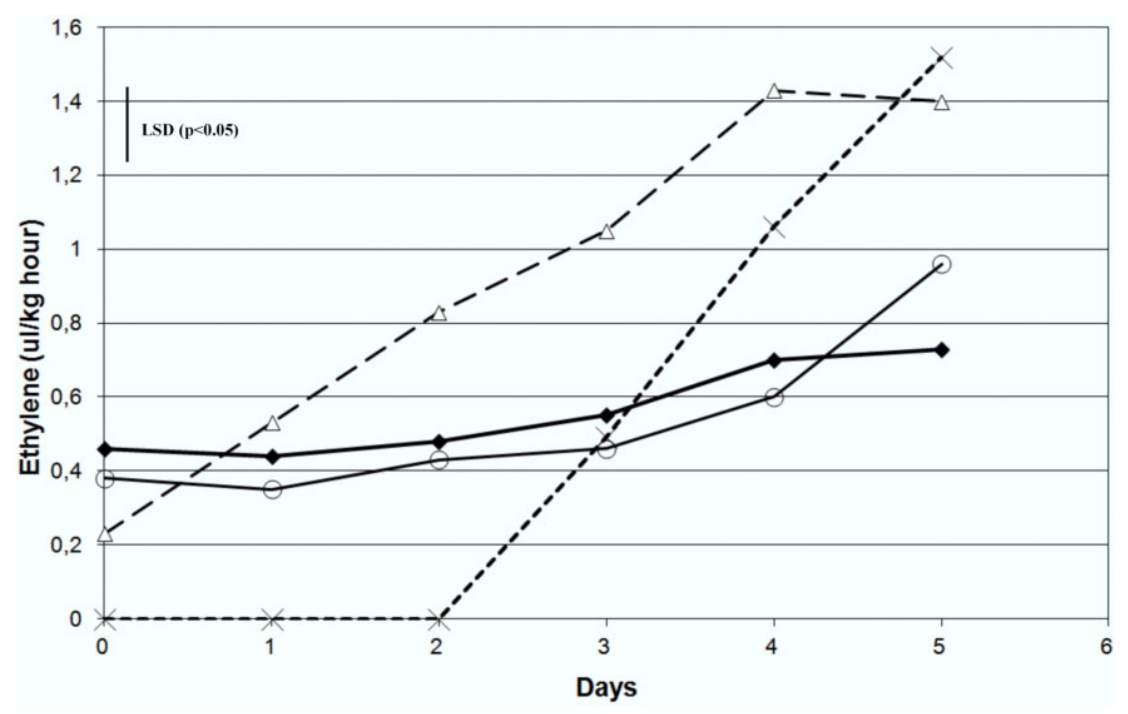

exposure of peaches for 3 days at high temperature prevented the increment in the level of transcript encoding ACC oxidase, which is normally found in fruit ripening at 20C. However, when heated fruits were transferred to 20C, a dramatic increase in transcripts was found, which almost doubled the level found in untreated fruit. Atta-Aly (1992) found in tomatoes maintained at $35 \mathrm{C}$ a rapid increase in ACC concentration, which paralleled an inhibition in ethylene synthesis. Lurie et al. (1996) linked this phenomenon to the decrease in the abundance of mRNA encoding ACC oxidase.

In the present research, we found that the exposure of fruits to heat for $48 \mathrm{~h}$ completely inhibited ethylene production, whose re-establishment required 2 days of exposure at 20C. This difference can be attributed to the particular characteristics of the tomato varieties used in each investigation.
The continuous increase in ethylene production observed in fruit subjected to cold treatment can be linked to the physiological breakdown caused by the cold exposure of sensitive fruits such as tomatoes (Artés et al. 1998). According to the results, ethylene production can be regarded as a suitable monitoring variable for heat, but not cold treatments. The fact that more than a single determination would be necessary to have a complete picture of the effect of treatments constitutes a drawback for the use of ethylene as a monitoring parameter.

\section{Stress Proteins}

Figure 5 shows SDS-PAGE of protein extracts from control (C) and treated tomatoes (HS24, HS48 and CS24). Fruits
FIG. 5. SODIUM DODECYL SULFATEPOLYACRYLAMIDE GEL ELECTROPHORESIS OF PROTEIN EXTRACTS FROM TOMATOES UNTREATED (C), HEAT-TREATED FOR $24 \mathrm{H}$ AND $48 \mathrm{H}$ (HS24 AND HS48) AND COLDTREATED FOR $24 \mathrm{H}$ (CS24)

Analyses were performed immediately after treatments (C, HS24, HS48 and CS24) and after $24 \mathrm{H}$ at $20 \mathrm{C}(\mathrm{C}+24, \mathrm{HS} 24+24$, $\mathrm{HS} 48+24, \mathrm{CS} 24+24)$.
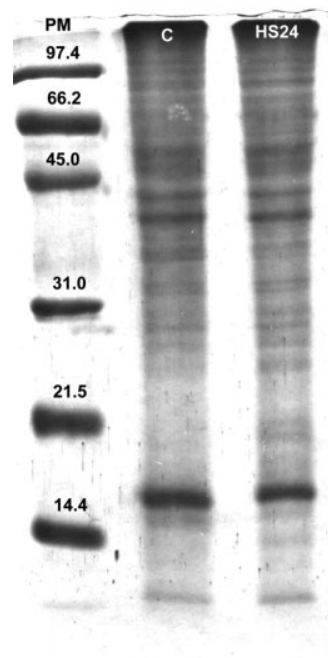
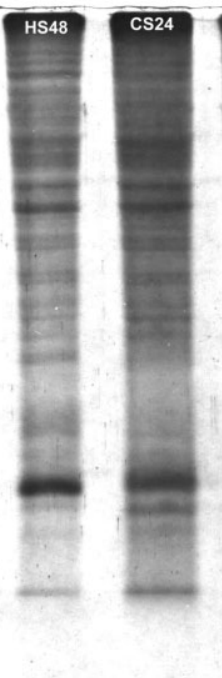
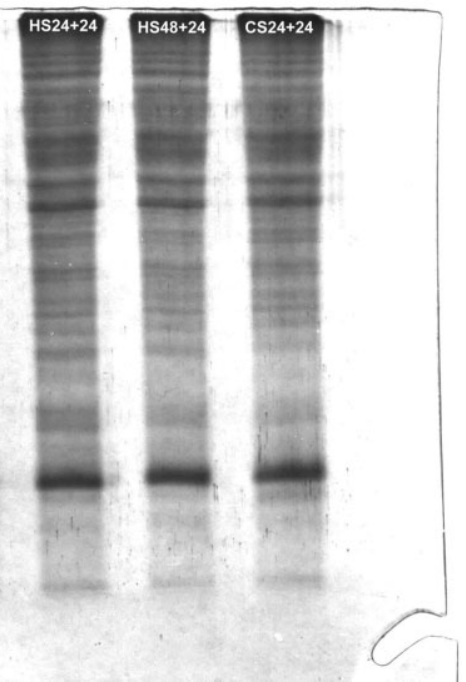


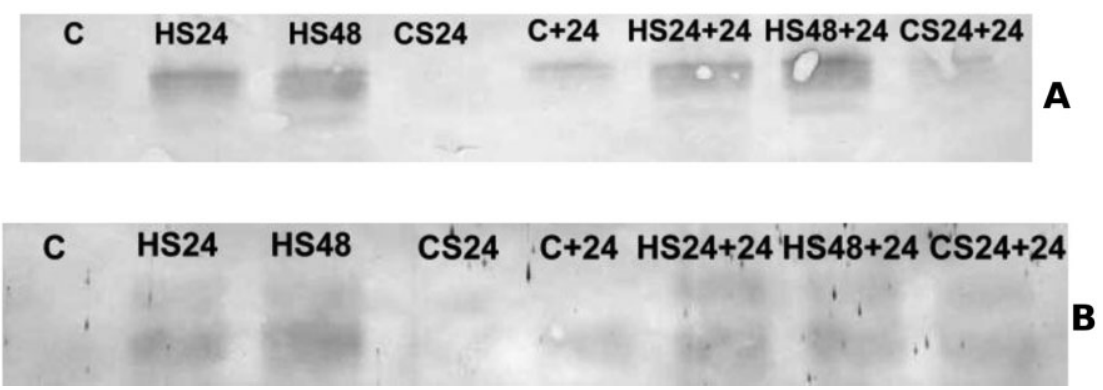

FIG. 6. WESTERN BLOT ANALYSIS FOR HSP7O $\begin{array}{ll}\text { (A) AND HSP21 } & \text { (B) OF PROTEIN EXTRACTS }\end{array}$ FROM TOMATOES UNTREATED (C), HEATTREATED FOR $24 \mathrm{H}$ AND $48 \mathrm{H}$ (HS24 AND HS48) AND COLD-TREATED FOR $24 \mathrm{H}$ (CS24) Analyses were performed immediately after treatments (C, HS24, HS48 and CS24) and after $24 \mathrm{H}$ at $20 \mathrm{C}(\mathrm{C}+24, \mathrm{HS} 24+24$, $\mathrm{HS} 48+24, \mathrm{CS} 24+24)$. were analyzed immediately after treatment and after incubation for additional $24 \mathrm{~h}$ at $20 \mathrm{C}$ to allow the induction and synthesis of proteins. No differences were found in SDSPAGE analysis between extracts from control and treated tomatoes in the region of $40-100 \mathrm{kDa}$. However, Western blot analysis showed an important accumulation of HSP70 proteins in heat-treated fruits (Fig. 6A), with band intensities being proportional to the duration of the heat exposure. After the incubation of the treated fruits for $24 \mathrm{~h}$ at $20 \mathrm{C}$, a slight induction of HSP70 was also found in control and cold-treated fruits.

In the region of low molecular weights $(15-30 \mathrm{kDa})$, the synthesis of new proteins was apparent in extracts from heated fruit (Fig. 5). A 25-kDa protein was detected in heattreated fruits immediately after treatment, which remained at a high concentration after $24 \mathrm{~h}$ at $20 \mathrm{C}$. This protein was detected in cold-treated fruits only after $24 \mathrm{~h}$ of exposure to 20C (CS24+24), but was not present in control fruit. Immediately after heat exposure, two $21-\mathrm{kDa}$ proteins accumulated at high concentrations in fruits subjected to high temperature treatments (HS24 and HS48), which remained at similar levels in fruits analyzed after $24 \mathrm{~h}$ at 20C. In Western blot analyses, two proteins of $21 \mathrm{kDa}$ were detected immediately after treatments by the anti-HSP21 antiserum in both HS24 and HS48 fruits. Interestingly, when fruits were analyzed after exposure at $20 \mathrm{C}$ for additional $24 \mathrm{~h}$, these proteins were also detected in cold-treated fruit (CS24; Fig. 6).

The accumulation of HSP had the best consistency among all the attributes included in the present study as candidates for monitoring purposes, showing its potentiality for use in both heat and cold treatments. One additional advantage is that the induction of HSP represents a common response to different types of stresses and to all plant tissues. This phenomenon was reported in several species such as tomatoes (Sabehat et al. 1996), soybean, pea, sunflower, wheat, rice, maize (Mansfield and Key 1987), strawberries (Civello et al. 1997) and papaya (Paull and Chen 1990). In the particular case of cold stress, low temperatures were found to exert a genetic control on the synthesis of some HSP (Neven et al. 1992). It is important to mention that not all HSP families have the capacity to respond to all types of stress. For instance, in the present research, Western blot analysis showed that HSP70 was able to act as a differential marker of heat but not of cold treatment (Fig. 6A).

Among the different HSP families, small heat shock protein (sHSP) constitutes probably the most appropriate for monitoring purposes, given the positive correlation found between the increased amounts of proteins and the treatment intensity, in addition to their feasibility of being induced by cold treatment (Fig. 6B). The present study showed that the accumulation of these proteins takes place only if fruits are exposed to $20 \mathrm{C}$ for $24 \mathrm{~h}$, subsequently to the treatment. The relationship between this induction and CI prevention remains to be demonstrated. In a previous investigation, Sabehat et al. (1998) found that low temperatures were able to induce the expression of two sHSP genes, provided that fruits had been previously exposed to high temperatures. Unfortunately, a condition similar to the one established in the present study (i.e., the exposition at a temperature of $20 \mathrm{C}$ following low temperature exposure) was not assayed. Kadyrzhanova et al. (1998) found that levels of transcripts associated with genes of the sHSP family increased in fruits chilled for 1 week and then transferred to $20 \mathrm{C}$, an evidence that supports the finding in the present research.

The two HSPs with the most relevant roles in CI protection are sHSP and HSP70 families. It has been speculated that the role played by sHSP in the acquisition of tolerance to $\mathrm{CI}$ is related to their chaperone activity and their participation in the stabilization of the plant cell membranes. The same mechanism is probably involved in other stress responses such as drought, salinity, pathogens, oxidative and wounding stresses (Wang et al. 2004; Sun et al. 2010). On the contrary, HSP70 probably acts by preventing the aggregation of non-native proteins under stress conditions and assisting in the refolding process. Other HSP members are involved in facilitating the proteolytic degradation of nonnative proteins (Zhang et al. 2005). All these processes contribute together to maintain the cellular homeostasis and therefore to withstand a severe stress condition.

It is important to highlight that although the resistance to CI has been linked to the overexpresion of HSP, the sole 
presence of these proteins does not completely explain the acquired tolerance to CI. Although a heat treatment may cause membrane alterations during its application, as reflected by the increase in membrane leakage, if properly applied, the integrity of tissues can be recovered after the heat removal, and the leakage can return to levels similar to those found in control tissues (Lurie and Klein 1990; Lurie 1998). This phenomenon reinforces the need to find a tool to monitor the limit of reversibility of stress treatments.

Referring back to previous investigations, it can be speculated that the synthesis of HSP induced by the exposure of fruits to cycles of low and high temperature could be involved in the protection exerted by a treatment termed "intermittent warming." This technology consists of removing the fruits from of the refrigerated storage and warming them for a short period, before resuming the cold storage. Interestingly, no convincing support has been found up until now to explain the basis of this treatment (Lill et al. 1989; Fernández-Trujillo and Artés 1997).

\section{Cl Symptoms}

Immediately after withdrawal from storage at 2C (for 21 and 28 days), neither control nor heat-treated fruits had symptoms of decay (data not shown). However, when fruits were then exposed for additional 7 days at 20C, Fig. 7 shows that CI was evident in control and cold-treated fruits, although the development of symptoms was successfully prevented by heat treatments. Thus, decay in untreated fruit attained $87 \%$ of the fruit stored for 21 days $(+7)$, and $100 \%$ of the fruit stored for 28 days $(+7)$. This was in contrast with heat-treated tomatoes, whose percentages of damage were considerable lower: $47 \%(21$ days +7$)$ and 60\% (28 days +7$)$ in HS24 treatment, and 20\% (21 days +7$)$ and
27\% (28 days +7 ) in HS48 treatment. Cold treatment was unsuccessful to prevent the development of CI, with fruits subjected to this treatment showing high levels of spoilage.

Concerning the effectiveness of each type of treatment, the present study shows that only heat treatments were able to prevent physiological damage of tomatoes under the conditions evaluated.

Heat treatment can be considered as a promising technology, taking into account that postharvest decay is the major factor limiting the extension of storage life of different fruit and vegetables such as tomatoes, and that nowadays consumers are very concerned about the use of chemicals in food (Sivakumar and Fallik 2013). The effectiveness of treatments relies on different factors such as the capacity to reduce from 3 to $4 \mathrm{log}$ the total microbial colony-forming units (cfu) of the microorganisms present on the peel, compared with untreated fruit (Fallik et al. 2000). Another factor is the capacity of treatment to redistribute the epicuticular wax layer, which reduces the peel cracks and avoids the penetration of pathogens (Schirra and D'Hallewin 1997).

Previous research also showed that tomatoes heated for 3 days and then stored for 3 weeks at 2C did not develop symptoms of CI (Lurie and Klein 1991; Lurie et al. 1993). According to our experience, an excessive exposure to the stress condition can have deleterious effect on fruits, provoking even higher percentages of decay in comparison to untreated fruit. Contrarily, milder treatments such as water dipping or short-term air treatments (for 24 or $48 \mathrm{~h}$ ) seem to be more effective. These pieces of evidence would indicate the existence of an "optimal treatment intensity," and the level of accumulation of sHSP can be a promising tool for the optimization of treatments.
FIG. 7. CHILLING INJURY INDEX MEASURED AS THE PERCENTAGE OF FRUITS SHOWING SYMPTOMS OF DECAY

Fruits were analyzed immediately after 21 and 28 days of storage +7 days at $20 \mathrm{C}$. Control, ( $\square$ ) HS24, ( $\square$ ) HS48, ( $\square$ ) CS24.

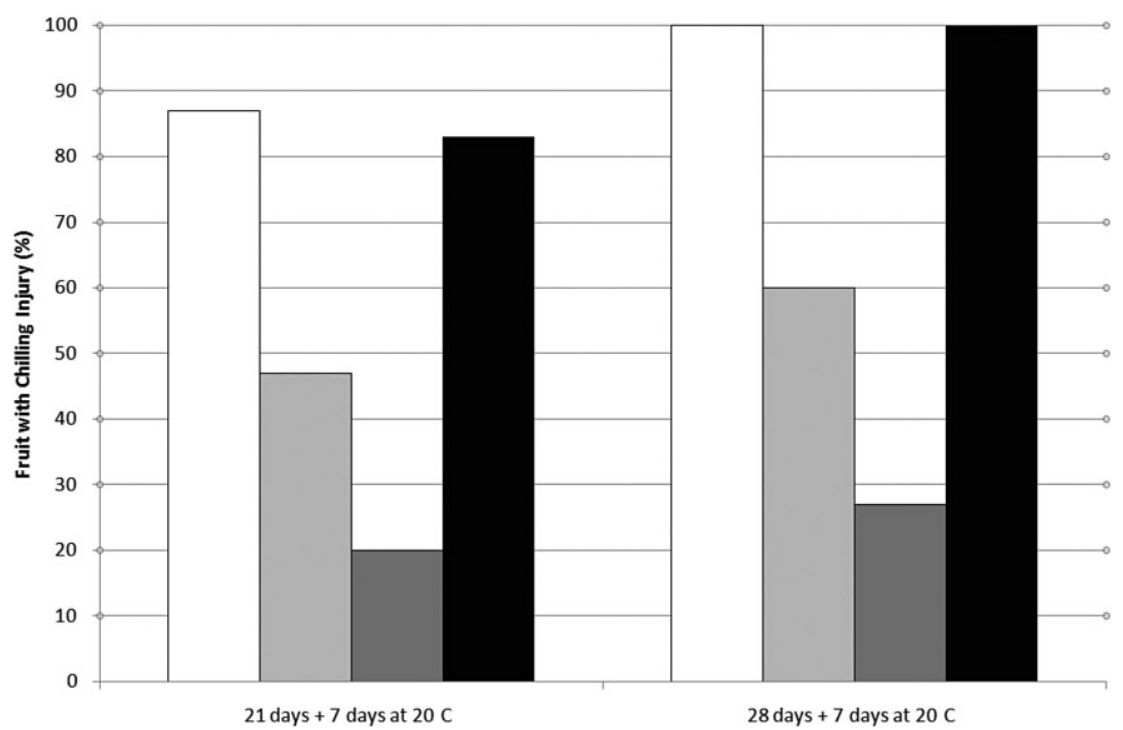


In the case of cold treatment, this study showed that the sole exposure of fruit to low temperature is insufficient to accumulate sHSP; therefore, an additional incubation at temperatures allowing the protein synthesis would be required. Considering the relationship between HSP accumulation and CI prevention, it remains to be proved whether this post-treatment, applied before the cold storage, represents a necessary step for the success of the treatment. Also, if this would be the case, the level of sHSPs would be a suitable parameter to corroborate that the required level of protection has been attained.

\section{CONCLUSIONS}

The results from the present and previous investigations make evident that the application of stress treatments constitutes a promising technology to reduce CI in susceptible commodities. However, a suitable performance can only be attained if treatment intensity is strictly controlled by a proper variable. According to the results, we propose sHSP accumulation as a monitoring variable to be measured in fruit prior to cold storage. The evaluation of this variable would permit the avoidance of either the overexposure of fruits to stress conditions resulting in deleterious treatments or the application of treatments at intensities insufficient to induce the accumulation of HSPs at the required level. Research to develop a simple and rapid immunological method to determine HSP concentration is currently in progress in our laboratory.

\section{ACKNOWLEDGMENT}

This research was supported by a grant (PNAIyAV-1130033) from Instituto Nacional de Tecnologia Agropecuaria (INTA-Argentina).

\section{REFERENCES}

AGHDAM, M., SEVILLANO, L., FLORES, F. and BODBODAK, S. 2013. Heat shock proteins as biochemical markers for postharvest chilling stress in fruits and vegetables. Sci. Hortic. 160, 54-64.

ARTÉS, F., GARCÍA, F., MARQUINA, J., CANO, A. and FERNÁNDEZ-TRUJILLO, J.P. 1998. Physiological responses of tomato fruit to cyclic intermittent temperature regimes. Postharvest Biol. Technol. 14, 283-296.

ATTA-ALY, M.A. 1992. Effect of high temperature on ethylene biosynthesis by tomato fruit. Postharvest Biol. Technol. 2, $19-24$.

CIVELlO, P., MARTÍNEZ, G., CHÁVES, A. and AÑÓN, M.C. 1997. Heat treatments delay ripening and postharvest decay of strawberry fruit. J. Agric. Food Chem. 45, 4589-4594.
DUMAS, Y., DADOMO, M., DI LUCCA, G. and GROLIER, P. 2002. Review of the influence of major environmental and agronomic factors on the lycopene content of tomato fruit. Acta Hortic. 579, 595-601.

EFIUVWEVWERE, B. and THORNE, S. 1988. Development of chilling injury symptoms in stored tomato fruit (Lycopevsicon esculentum Mill). J. Sci. Food Agric. 44, 215-226.

EL ASSI, N. 2004. Alleviating chilling injury and maintaining quality of tomato fruit by hot water treatments. Emir. J. Agric. Sci. 16, 1-7.

FALLIK, E., AHARONI, Y., COPEL, A., RODOV, R., TUVIA-ALKALAI, S., HOREV, B., YEKUTIELI, O., WISEBLUM, A. and REGEV, R. 2000. A short hot water rinse reduces postharvest losses of "Galia" melon. Plant Pathol. 49, 333-338.

FERNÁNDEZ-TRUJILLO, J. and ARTÉS, F. 1997. Keeping quality of cold stores peaches using intermittent warming. Food Res. Int. 30, 441-450.

HURKMAN, W.L. and TANAKA, C.K. 1986. Solubilization of plant membrane proteins for analysis by two-dimensional gel electrophoresis. Plant Physiol. 81, 802-806.

KADYRZHANOVA, D., VLACHONASIOS, K., VERVERIDIS, P. and DILLEY, D. 1998. Molecular cloning of a novel heat induced/chilling tolerant related cDNA in tomato fruit by use of mRNA differential display. Plant Mol. Biol. 36, 885-895.

LAEMMLI, U.K. 1970. Cleavage of structural proteins during the assembly of the head of bacteriofage $\mathrm{T}_{4}$. Nature 227 , 680-685.

LARA, M., BORSANI, J., BUDDE, C., LAUXMANN, M., LOMBARDO, V., MURRAY, R., ANDREO, C. and DRINCOVICH, M. 2009. Biochemical and proteomic analysis of "Dixiland" peach fruit (Prunus persica) upon heat treatment. J. Exp. Bot. 60, 4315-4333.

LILL, R., O’DONOGHUE, E. and KING, G. 1989. Postharvest physiology of peaches and nectarines. Hortic. Rev. 11, 413-452.

LOWRY, O.H., ROSEBROUGH, N.J., FARR, A.L. and RANDALL, R.J. 1951. Protein measurement with the Folin phenol reagent. J. Biol. Chem. 193, 265-275.

LURIE, S. 1998. Postharvest heat treatments. Postharvest Biol. Technol. 14, 257-269.

LURIE, S. and KLEIN, J.D. 1990. Heat treatment on ripeness apples: Differential effects on physiology and biochemistry. Physiol. Plant. 78, 181-186.

LURIE, S. and KLEIN, J.D. 1991. Acquisition of low temperature tolerance in tomatoes by exposure to high temperature stress. J. Am. Soc. Hortic. Sci. 116, 1007-1012.

LURIE, S., KLEIN, J.D., WATKINS, C., ROSS, G., BOSS, P. and FERGUSON, I.F. 1993. Prestorage heat treatment of tomatoes prevents chilling injury and reversibly inhibits ripening. Acta Hortic. 343, 283-285.

LURIE, S., HANDROS, A., FALLIK, E. and SHAPIRA, R. 1996. Reversible inhibition of tomato fruit gene expression at high temperature. Effects on tomato fruit ripening. Plant Physiol. 110, 1207-1214. 
MANSFIELD, M. and KEY, J. 1987. Synthesis of the low molecular weight heat shock proteins in plants. Plant Physiol. 84, 1007-1017.

MANZANO-MENDEZ, J., HICKS, J. and MASTERS, J. 1984. Influence of storage temperature and ethylene on firmness, acids, and sugars of chilling sensitive and chilling tolerant tomato. J. Am. Soc. Hortic. Sci. 109, 273-277.

MCDONALD, R., MCCOLLUM, T. and BALDWIN, E. 1998. Heat treatment of mature-green tomatoes: Differential effects of ethylene and partial ripening. J. Am. Soc. Hortic. Sci. 123, 457-462.

NEVEN, L., HASKELL, D., GUY, C., DENSLOW, N., KLEIN, P., GREEN, L. and SILVERMAN, A. 1992. Association of 70-kilodalton heat-shock cognate proteins with acclimation to cold. Plant Physiol. 99, 1362-1369.

PAULL, R. and CHEN, N. 1990. Heat shock response in field-grown, ripening papaya. J. Am. Soc. Hortic. Sci. 115, 623-631.

PAULL, R. and CHEN, N. 2000. Heat treatment and fruit ripening. Postharvest Biol. Technol. 21, 21-37.

PAULL, R.E. 1990. Chilling injury of crops of tropical and subtropical origin. In Chilling Injury of Horticultural Crops (C.Y. Wang, ed.) pp. 17-36, CRC Press, Boca Raton, FL.

POLENTA, G., BUDDE, C., LUCANGELI, C. and MURRAY, R. 2004. Logarithmic transformation to perform statistical analysis of ethylene production in peaches. Rev. Iber. Technol. Postcosecha 6, 1-6.

POLENTA, G., LUCANGELI, C., BUDDE, C., GONZALEZ, C.B. and MURRAY, R. 2006. Heat and anaerobic treatments affected physiological and biochemical parameters in tomato fruits. LWT - Food Sci. Technol. 39, 27-34.

POLENTA, G., CALVETE, J.J. and GONZALEZ, C.B. 2007. Isolation and characterization of the main small heat shock proteins induced in tomato pericarp by thermal treatment. FEBS J. 274, 6447-6455.

SABEHAT, A., WEISS, D. and LURIE, S. 1996. The correlation between heat-shock protein accumulation and persistence and chilling tolerance in tomato fruit. Plant Physiol. 110, 531-537.
SABEHAT, A., LURIE, S. and WEISS, D. 1998. Expression of small heat-shock proteins at low temperatures. A possible role in protecting against chilling injury. Plant Physiol. 117, 651-658.

SCHIRRA, M. and D'HALLEWIN, G. 1997. Storage performance of Fortune mandarins following hot water dips. Postharvest Biol. Technol. 10, 229-237.

SIVAKUMAR, D. and FALLIK, E. 2013. Influence of heat treatments on quality retention of fresh and fresh-cut produce. Food Rev. Int. 29, 294-320.

SOZZI, G., CASCONE, O. and FRASCHINA, A. 1996. Effect of a high temperature stress on endo- $\beta$-mannase and endo- $\beta$-galactosidase activities during tomato fruit ripening. Postharvest Biol. Technol. 9, 49-63.

SUN, J., CHEN, J., KUANG, J., CHEN, W. and LU, W. 2010. Expression of sHSP genes as affected by heat shock and cold acclimation in relation to chilling tolerance in plum fruit. Postharvest Biol. Technol. 55, 91-96.

SUNG, D.Y., KAPLAN, F., LEE, K.J. and GUY, C.L. 2003. Acquired tolerance to temperature extremes. Trends Plant Sci. 8, 179-187.

THOMSOM, J. and CRISOSTO, C., eds. 2010. Fruit Ripening and Ethylene Management, Postharvest Technology Research \& Information Center, UC Davis, Davis, CA, USA. $130 \mathrm{pp}$.

USDA. 1976. United States Standards for Grades of Fresh Tomatoes. US Dept. Agric. Mktg Serv, Washington, DC. WANG, W., VINOCUR, B., SHOSEYOV, O. and ALTMAN, A. 2004. Role of plant heat-sock proteins and molecular chaperones in the abiotic stress response. Trends Plant Sci. 9, 244-252.

WOOLF, A., COX, K., WHITE, A. and FERGUSON, I. 2003. Low temperature conditioning treatments reduce external chilling injury of "Haas" avocados. Postharvest Biol. Technol. 28, 113-122.

ZHANG, J., HUANG, W., PAN, Q. and LIU, Y. 2005. Improvement of chilling tolerance and accumulation of heat shock proteins in grape berries (Vitis vinifera $\mathrm{cv}$. Jingxiu) by heat pretreatment. Postharvest Biol. Technol. 38, 80-90. 